Original Research Article

\title{
A Comparative study to assess the effectiveness and safety of cilnidipine versus amlodipine in patients with newly diagnosed essential hypertension: insights from a single centre prospective observational study
}

\author{
Ramya Y. S. ${ }^{1}$, Jayanthi C. R. ${ }^{1}$, Raveendra K. R. ${ }^{2}$, Pradeep Kumar B. T. ${ }^{1}$
}

${ }^{1}$ Department of Pharmacology, Bangalore Medical College and Research Institute Bangalore, Karnataka, India

${ }^{2}$ Department of Medicine, Bangalore Medical College and Research Institute Bangalore, Karnataka, India

Received: 19 December 2016 Accepted: 13 January 2017

*Correspondence to:

Dr. Ramya Y. S.,

Email:

ramyasrinivas14@gmail.com

Copyright: (C) the author(s), publisher and licensee Medip Academy. This is an openaccess article distributed under the terms of the Creative Commons Attribution NonCommercial License, which permits unrestricted noncommercial use, distribution, and reproduction in any medium, provided the original work is properly cited.

\begin{abstract}
Background: Calcium channel blockers $(\mathrm{CCBs})$ are proposed to play a pivotal role for the management and control of hypertension. Dihydropyridine-type calcium channel blockers (CCBs) like Amlodipine are frequently used because for their strong antihypertensive and minimal adverse side effects. However, it is commonly associated with the causation of pedal edema among the patients. Cilnidipine, which is a novel new generation calcium channel blocker, is presumed to cause lesser pedal edema with a satisfactory clinical control of hypertension along with negligible side effects. This study was carried out to compare clinical effectiveness and safety profile between Amlodipine and Cilnidipine.

Methods: A prospective, randomized, open label study of 12 weeks' duration was conducted amongst 60 patients with newly diagnosed essential hypertension. 30 patients of one group received Tab. Amlodipine $5 \mathrm{mg}$ and 30 patients of same age groups received Tab. Cilnidipine 10mg.

Results: There was a highly statistically significant decrease in the level of blood pressure in the Cilnidipine group compared to the Amlodipine group mainly at day $90(\mathrm{P}<0.001)$. Cilnidipine treated group had a fall in blood pressure of $23 \pm 8 \mathrm{mmHg}$ and the Amlodipine group had a decrease in the blood pressure of $12 \pm 7 \mathrm{mmHg}$. Additionally, there was also significant reduction in pulse rate in the cilnidipine group. Only 4 patients in the Cilnidipine group developed ankle edema which completely disappeared at the end of 12 weeks of therapy compared to 9 patients in the Amlodipine group which persistently worsened at the completion of the study.

Conclusions: Our study concluded that cilnidipine was a well-tolerated antihypertensive drug amongst patients with newly diagnosed essential hypertension and associated with minor adverse effects.
\end{abstract}

Keywords: Amlodipine, Ankle edema, Cilnidipine, Newly diagnosed essential hypertension

\section{INTRODUCTION}

Globally around 1 billion individuals are affected by hypertension. Estimates in India indicate that around 30\% population in India is affected with systemic hypertension. ${ }^{1}$ Additionally; Hypertension is commonly associated with diabetes mellitus, physical inactivity, excessive salt intake, smoking and obesity and is also a crucial risk factor for cardiovascular, neurological, kidney and peripheral vascular disorders. ${ }^{2}$

In the therapeutic armamentarium of antihypertensive drugs, calcium channel blockers (CCBs) are proposed to play a pivotal role for the management and control of hypertension. Dihydropyridine-type calcium channel blockers (CCBs) are frequently used because of their strong BP-lowering properties and minimal adverse side 
effects. Traditionally, Amlodipine has been used as the CCB of choice owing to its satisfactory pharmacokinetic and pharmacodynamic profile. ${ }^{3}$

One of the most disturbing side effects of Amlodipine is its tendency to cause pedal edema with an average incidence rate of $15 \%(1.7 \%$ to $32 \%) .{ }^{4}$ Among the different sub-types of calcium channels, the N-type channel is considered to be involved in the activation of RAS leading to the release of catecholamines (Norepinephrine). There is an emerging trend to use dual $\mathrm{N}$ and L-type calcium channel blockers as it has been proposed that its use has a less possibility of the RAS. ${ }^{5}$

Cilnidipine, a third-generation combined L/N-type CCB, is approved for the treatment of essential hypertension. ${ }^{6}$ Moreover, it has also been proposed to provide with an action profile that goes beyond the antihypertensive effect like lowering the incidence of untoward side effects like ankle edema.

This study was therefore conducted to evaluate the effectiveness and safety of Tab. Cilnidipine $10 \mathrm{mg}$ compared to Tab. Amlodipine 5mg, in patients with newly diagnosed essential hypertension.

\section{METHODS}

A 12-week randomized, prospective, open label, observational study was conducted at the Department of Medicine, Bangalore Medical College and Research Institute, Bangalore, India between October 2014, and December 2014. Approval of the Institutional Ethics Committee and patient consent were obtained prior to the study.

Institutional Ethics Committee clearance was obtained for the study and the patients fulfilling inclusion and exclusion criteria were enrolled in the study.

A total of 60 patients (30patients in each group), during the study period were randomized to receive either Tab. Amlodipine $5 \mathrm{mg}$ or Tab. Cilnidipine $10 \mathrm{mg}$ orally once a day in the morning.

\section{Inclusion criteria}

As per the full prescribing information for the study drugs:

- Patients willing to give informed written consent for the study.

- Newly diagnosed adult patients of essential hypertension aged 18-75 years attending the OPD of General Medicine Department of Victoria Hospital (according to JNC 8).

\section{Exclusion criteria}

- Patients not willing to consent for the study
- $\quad$ Patients aged $<18$ and $>75$ years of age.

- Pregnant and lactating women.

- Defaulters to the prescribed follow up.

- Patients with recurrent symptomatic hypotension.

- Patients with prior history of Angina/ Myocardial infarction/ CVA/TIA.

- Patients with diagnosed uncontrolled diabetes mellitus, hepatic and renal impairment.

- Patients with severe hypertension

A total 60 patients $(n=60)$ were recruited in the study with 30 patients in each group. All BP measurements were taken in a seated position, having rested for 10 minutes (WHO criteria). The blood pressure was measured in right arm, sitting posture by the auscultatory method using standard mercury sphygmomanometer. Three separate BP measurements were recorded with at least 1 minute interval between the measurements. The mean of the three measurements were used as the BP value for that visit.

Side effects like Pedal edema if any was assessed over the medial malleolus of both legs. Presence of pedal edema on either of the legs was considered as positive for the pedal edema.

After initial screening and patient consenting for the study, demographic data, past medical history, family history, and findings of clinical examination were recorded.

Patients were randomized into two groups and were prescribed either Tab. Amlodipine $5 \mathrm{mg}$ or Tab. Cilnidipine $10 \mathrm{mg}$ orally once daily in the morning.

These 60 patients in the study group were followed every 30 days or three more visits (There were a total of 4 visits including baseline for the study). In every visit, the patients were evaluated for the control of hypertension and assessed for side effects if any.

\section{RESULTS}

All the study participants completed the study and there was no loss to follow-up. Patient's age for both the groups ranged between 30 and 75 years, with the mean age being $55.75 \pm 9.7$ years in the amlodipine group and $53.45 \pm 8.9$ years in cilnidipine group (Table 1).

Table 1: Age wise distribution of study subjects.

\begin{tabular}{|llll|}
\hline Age (In years) & Amlodipine & Cilnidipine & Total \\
\hline $30-45$ & $3(10)$ & $3(10)$ & $6(10)$ \\
\hline $46-60$ & $18(60)$ & $16(53.3)$ & $34(56.6)$ \\
\hline $61-75$ & $9(30)$ & $11(36.6)$ & $20(33.3)$ \\
\hline Total & 30 & 30 & 60 \\
\hline
\end{tabular}

As per the table, most of the patients in both the groups were in the age group of 46-60 years. 
In our study, Men were more than women in the sex wise distribution of study subjects as mentioned in Table 2 .

Table 2: Sex wise distribution of study subjects.

\begin{tabular}{|llll|}
\hline Gender & Amlodipine & Cilnidipine & Total \\
\hline Male & $19(63.3)$ & $22(73.3)$ & $41(68.3)$ \\
\hline Female & $11(36.6)$ & $8(26.6)$ & $19(31.6)$ \\
\hline Total & 30 & 30 & 60 \\
\hline
\end{tabular}

Table 3: Baseline BP of study subjects.

\begin{tabular}{|lll|}
\hline & $\begin{array}{c}\text { Amlodipine } \\
(\text { Mean } \pm \text { SD })\end{array}$ & $\begin{array}{l}\text { Cilnidipine } \\
(\text { Mean } \pm \text { SD })\end{array}$ \\
\hline SBP & $158.1 \pm 8.2$ & $162.3 \pm 8.8$ \\
\hline DBP & $101.2 \pm 2.6$ & $101.8 \pm 4.4$ \\
\hline MAP & $120.2 \pm 3.7$ & $122.0 \pm 4.9$ \\
\hline PR & $78.1 \pm 9.8$ & $88.3 \pm 9.5$ \\
\hline
\end{tabular}

The baseline values of blood pressures of study participants are mentioned in Table 3.

There was a statistically significant decrease in the level of blood pressure in the Cilnidipine group compared to the Amlodipine group $(\mathrm{P}<0.05)$ at Day 90 as shown in Table 4

Table 4: SBP during the follow up visits.

\begin{tabular}{|llll|}
\hline SBP & $\begin{array}{l}\text { Amlodipine } \\
\text { Mean } \pm \text { SD }\end{array}$ & $\begin{array}{l}\text { Cilnidipine } \\
\text { Mean } \pm \text { SD }\end{array}$ & P - value \\
\hline Baseline & $158.1 \pm 8.2$ & $162.3 \pm 8.8$ & 0.06 \\
\hline Day 30 & $150.5 \pm 5.7$ & $147.1 \pm 8.4$ & 0.071 \\
\hline Day 60 & $145.0 \pm 6.2$ & $142.2 \pm 6.1$ & 0.082 \\
\hline Day 90 & $146.3 \pm 7.7$ & $137.8 \pm 6.1$ & $<0.001$ \\
\hline
\end{tabular}

The SBP during follow-up visits are tabulated and the corresponding $\mathrm{P}$-value is indicated as per the Table 5.

Table 5: SBP during follow up visits from baseline.

\begin{tabular}{|lllll|}
\hline Type of visit & & Amlodipine & Cilnidipine & P - value \\
\hline \multirow{2}{*}{ Baseline } & Stage 1 & $15(50)$ & $10(33.3)$ & 0.270 \\
\cline { 2 - 5 } & Stage 2 & $15(50)$ & $20(66.6)$ & \multirow{2}{*}{0.662} \\
\hline \multirow{2}{*}{ Day 30 } & Pre-hypertension & $0(0.0)$ & $4(13.3)$ & \\
\cline { 2 - 5 } & Stage 1 & $26(86.6)$ & $24(80.0)$ & \multirow{2}{*}{0.234} \\
\cline { 2 - 5 } \multirow{2}{*}{ Day 60 } & Stage 2 & $4(13.3)$ & $2(6.6)$ & 0.002 \\
\hline \multirow{2}{*}{ Day 90 } & Pre-hypertension & $6(20)$ & $10(33.3)$ & $20(66.6)$ \\
\cline { 2 - 5 } & Stage 1 & $24(80)$ & $16(53.3)$ & $14(46.7)$ \\
\hline
\end{tabular}

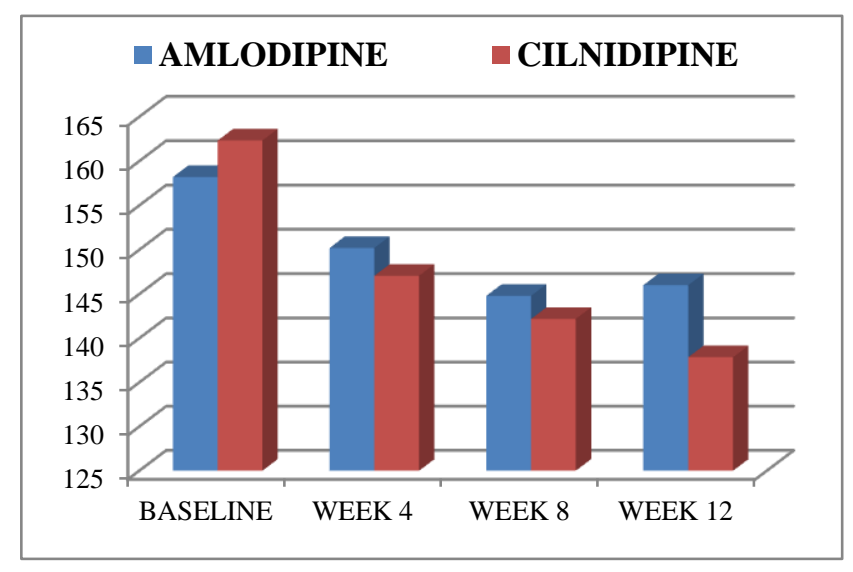

Figure 1: The comparison of mean systolic and diastolic BP between both groups.

Cilnidipine treated group having a fall in blood pressure of $23 \pm 8 \mathrm{mmHg}$ and the Amlodipine group having a decrease in the blood pressure of $12 \pm 7 \mathrm{mmHg}$ and significant reduction in pulse rate in the cilnidipine group as mentioned in the Figure 2.

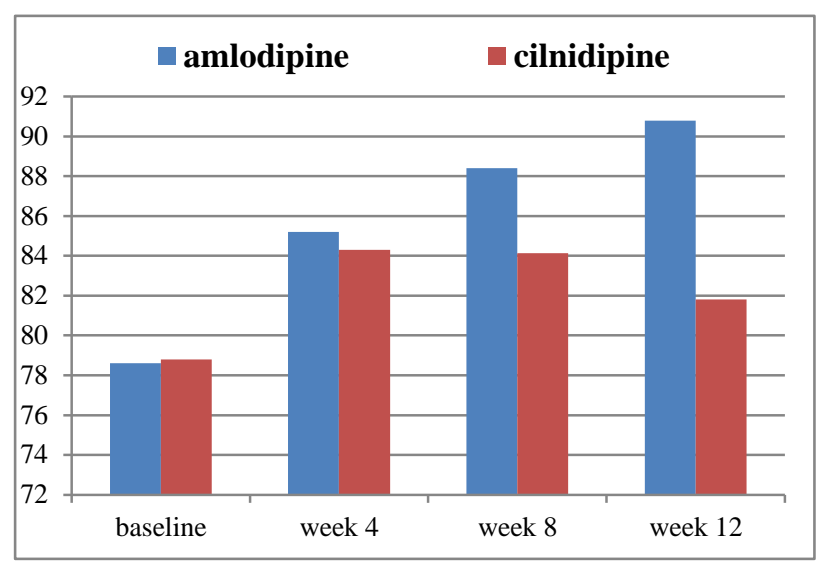

Figure 2: The comparison of pulse rates between both groups.

With regards to the side effects caused only 4 patients in the Cilnidipine group developed ankle edema which completely disappeared at the end of 12 weeks of therapy compared to 9 patients in the Amlodipine group which persistently worsened at the completion of the study (Figure 3, 4 and 5). 


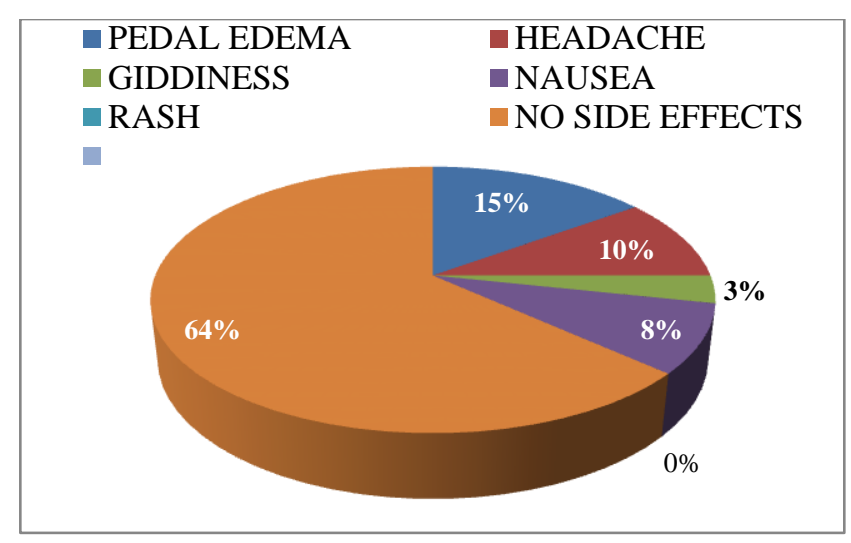

Figure 3: Side effects caused by Amlodipine.

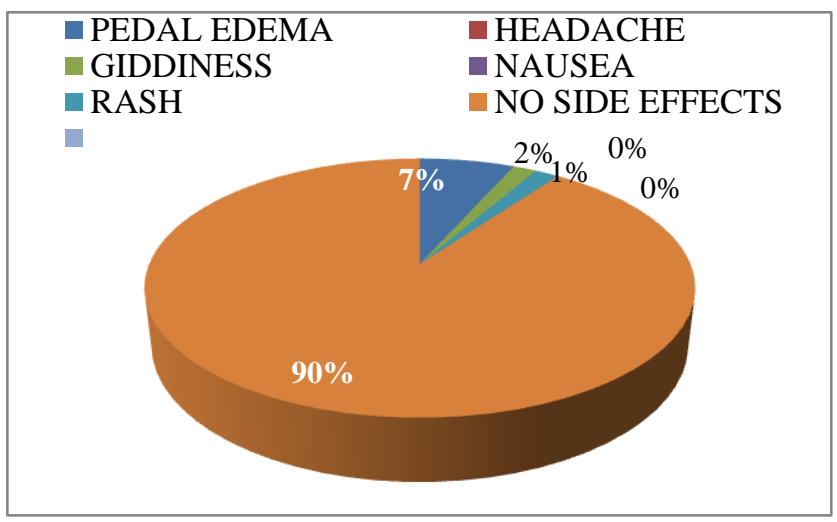

Figure 4: Side effects caused by Cilnidipine.

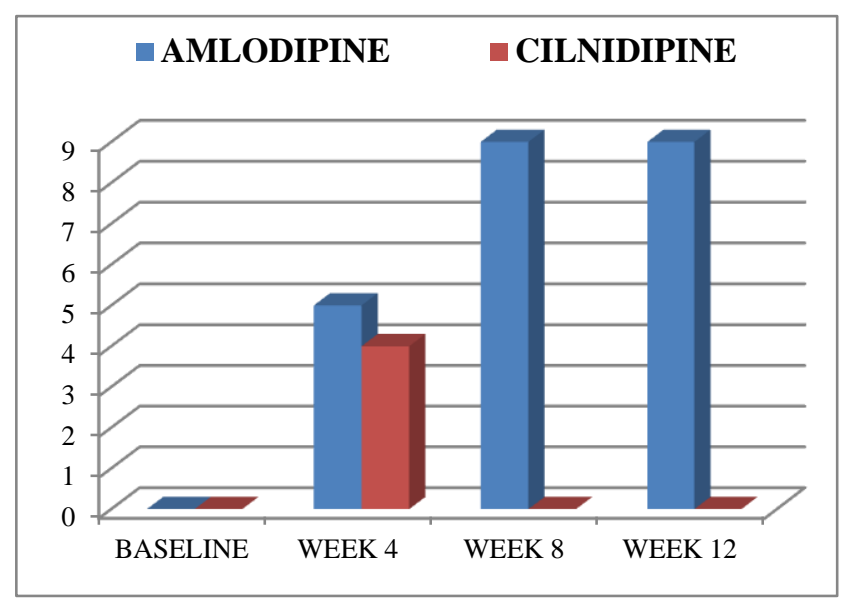

Figure 5: Incidence of pedal edema in both the groups.

\section{DISCUSSION}

In this study once daily use of Cilnidipine significantly reduced the $\mathrm{BP}$ compared to Amlodipine without causing an increase in PR. This is relevant because various studies have demonstrated that a higher heart rate is associated with a long-term risk of cardiovascular mortality, independent of other cardiac risk factors. ${ }^{7}$
Cilnidipine also acts on the N-type calcium channels which are distributed in the neurons and have an important role in regulating sympathetic activity. ${ }^{8}$ It is a 1,4- DHP CCB that suppresses the influx of calcium ions via L-type and $\mathrm{N}$-type calcium channels, thus reducing the blood pressure through vascular smooth muscle relaxation and arterial dilatation. ${ }^{9}$ Cilnidipine is known to suppress catecholamine release from peripheral sympathetic nerves as it blocks N-type channels in sympathetic nerve terminals as well as having a common L-type calcium channel-blocking effect. ${ }^{10}$

When administered to the patients with essential hypertension, cilnidipine suppressed cardiac sympathetic over activity and an increase of heart rate with blood pressure reduction. ${ }^{11}$

Our study has also shown that cilnidipine is welltolerated by the hypertensive patients and associated with minor adverse effects such as headache, dizziness, cough, and gastrointestinal symptoms which are comparable to amlodipine.

Funding: No funding sources

Conflict of interest: None declared

Ethical approval: The study was approved by the Institutional Ethics Committee

\section{REFERENCES}

1. Chobanian AV, Bakris GL, Black HR, Cushman WC, Green LA, Izzo JL, et al. The Seventh Report of the Joint National Committee on Prevention, Detection, Evaluation, and Treatment of High Blood Pressure: The JNC 7 report. JAMA. 2003;289:2560-72.

2. Calhoun DA, Jones D, Textor S, Goff DC, Murphy $\mathrm{TP}$, Toto RD, et al. Resistant hypertension: Diagnosis, evaluation, and treatment: A scientific statement from the American Heart Association Professional Education Committee of the Council for High Blood Pressure Research. Circulation. 2008;117:e510-26.

3. Kloke HJ, Branten AJ, Huysmans FT. Antihypertensive treatment of patients with proteinuric renal diseases: risks or benefits of calciumchannel blockers? Kidney Int. 1998;53:155973.

4. The safety of amlodipine. Osterloh I Am Heart J. 1989 Nov;118(5 Pt 2):1114-9.

5. Xu G, Wu H, Du B, Qin L. The efficacy and safety of cilnidipine on mild to moderate essential hypertension: A systematic review and meta-analysis of randomized controlled trials in Chinese patients. Cardiovasc Hematol Disord Drug Targets. 2012;12:56-62.

6. Chandra KS, Ramesh G. The fourth-generation Calcium channel blocker: Cilnidipine. Indian Heart Journal. 2013;65(6):691-5.

7. Gillman MW, Kannel WB, Belanger A, Agostino RB. Influence of heart rate on mortality among 
person with hypertension: the Framingham Study. Am Heart J. 1993;125:1148-54.

8. Sataka K, Shirotani M, Yoshida H. Effects of Amlodipine and Cilnidipine on cardiac sympathetic nervous system and neuro hormonal status in essential hypertension. Hypertension. 1999;33:144752.

9. Morimoto S, Takeda K, Oguni A. Reduction of white coat effect by Cilnidipine in essential hypertension. Am J Hypertens. 2001;14:1053-7.

10. Zhou X, Ono H, Ono Y, Frohlich ED. N-and L-type calcium channel antagonist improves glomerular dynamics, reverse severe nephrosclerosis and inhibits apoptosis and proliferation in an LNAME/SHR model. J Hypertens. 2002;20:993-1000.
11. Fujita T, Ando K, Nishimura H, Ideura T, Yasuda G, Takahashashi K. Antiproteinuric effect of the calcium channel blocker Cilnidipine added to rennin angiotensin inhibition in hypertensive patients with chronic renal disease. Kidney Int. 2007;72:1543-9.

Cite this article as: Ramya YS, Jayanthi CR,

Raveendra KR, Kumar PBT. A Comparative study to assess the effectiveness and safety of cilnidipine versus amlodipine in patients with newly diagnosed essential hypertension: insights from a single centre prospective observational study. Int J Basic Clin Pharmacol 2017;6:648-52. 